Research Article

\title{
Effect of CTAB Ratio to the Characters of Mesoporous Silica Prepared from Rice Husk Ash in the Pyrolysis of $\alpha$-cellulose
}

\author{
Nia Meisa Wulandari ${ }^{1}$, Lisna Efiyanti ${ }^{2, *}$, Wega Trisunaryanti ${ }^{3}$, Haryo Satriya Oktaviano ${ }^{1}$, \\ Syaiful Bahri ${ }^{4}$, Yatim Lailun Ni'mah ${ }^{5}$, Savitri Larasati ${ }^{3}$
}

${ }^{1}$ Department of Chemistry, Faculty of Science and Computer Science, Pertamina University, Teuku Nyak Arief, Simprug, Kebayoran Lama, Jakarta 12220, Indonesia.

${ }_{2}^{2}$ Forest Products Research and Development Center, The Ministry of Environment and Forestry, Bogor, 16610, Indonesia.

${ }^{3}$ Department of Chemistry, Faculty of Mathematics and Natural Science, Universitas Gadjah Mada, Yogyakarta, 55281, Indonesia.

${ }^{4}$ Department of Chemical Engineering, Faculty of Engineering, University of Riau, Pekanbaru, Indonesia. ${ }^{5}$ Department of Chemistry, Faculty of Mathematics and Natural Science, Sepuluh November Institute of Technology, Surabaya, 60111, Indonesia.

Received: 14 ${ }^{\text {th }}$ April 2021; Revised: 30th June 2021; Accepted: 1st July 2021

Available online: $5^{\text {th }}$ July 2021; Published regularly: September 2021

\section{Abstract}

Due to its wide application, synthesizing silica through a cost-effective process becomes an attractive subject to be studied today. In this work, mesoporous silica (MS) was prepared from the highly available agricultural waste, rice husk ash (RHA), to be used as catalyst in the pyrolysis of $\alpha$-cellulose. Silica was extracted from RHA through a reflux process in a strong base solution and arranged into a mesoporous structure by using cetyltrimethylammonium bromide (CTAB). To find a condition that produces a mesoporous support with the highest surface area and catalytic activity, the mole ratios of CTAB: $\mathrm{SiO}_{2}$ used during the preparation of MS were varied; 0.05:1;0.1:1;0.2:1. Afterwards, all prepared MS were characterized using Fourier Transform Infra Red (FTIR), Scanning Electron Microscope (SEM), and Surface Area Analyzer (SAA). Through he surface area analysis, it was found that MS materials possessed surface area, pore diameter, and pore volume that range from $600-970 \mathrm{~m}^{2} . \mathrm{g}^{-1}, 3.5-4.7 \mathrm{~nm}, 0.7-1$ $\mathrm{cm}^{3} \cdot \mathrm{g}^{-1}$, respectively. The highest surface area, with over $970.80 \mathrm{~m}^{2} \cdot \mathrm{g}^{-1}$, was obtained in MS support prepared by using CTAB: $\mathrm{SiO}_{2}$ mole ratio of 0.1:1. SEM images showed a coral reef-like surface morphology for all MS. In the pyrolysis of $\alpha$-cellulose evaluated by Py-GCMS, aside from producing biofuel compounds, the use of MS was able to generate two-fold furan production, which is considered as a valuable compound in many chemical syntheses. This result highlights the potential of MS prepared from RHA to be used as a catalysis support material that is more economical for biofuel and other chemical production.

Copyright (C) 2021 by Authors, Published by BCREC Group. This is an open access article under the CC BY-SA License (https://creativecommons.org/licenses/by-sa/4.0).

Keywords: $\alpha$-cellulose; mesoporous silica; pyrolysis; rice husk; CTAB

How to Cite: N.M. Wulandari, L. Efiyanti, W. Trisunaryanti, H.S. Oktaviano, S. Bahri, Y.L. Ni'mah, S. Larasati (2021). Effect of CTAB Ratio to the Characters of Mesoporous Silica Prepared from Rice Husk Ash in the Pyrolysis of $\alpha$-cellulose. Bulletin of Chemical Reaction Engineering \& Catalysis, 16(3), 632-640 (doi:10.9767/bcrec.16.3.10828.632-640)

Permalink/DOI: https://doi.org/10.9767/bcrec.16.3.10828.632-640

\section{Introduction}

Due to its non-renewable property and envi-

* Corresponding Author.

Email: lisnaefiyanti@gmail.com (L. Efiyanti);

Phone: (+62) 81315788573 ronmentally harmful emission, the use of fossil fuels as a primary energy source is no longer deemed to be desirable [1]. This concern has prompted numerous searches for a more feasible and sustainable alternative energy over the years. Biomass, for instance, is one of the most 
popularly studied alternative source that exhibits a promising potential with its high availability, renewability, and environmentally friendly nature [2]. Currently, energy production from biomass is especially focused on the conversion of cellulose, as one of its predominant compounds, into biofuel [3]. Being the most abundant polysaccharide on Earth, utilizing cellulose for alternative fuel production is appealing for the fact that it is cost-effective and does not interfere with food production [4]. The conversion of cellulose into liquid biofuel is mainly done through a thermochemistry process called pyrolysis that produces a mixture of oxygenated compounds referred as bio-oil [5]. However, although producing a cleaner emission during its combustion, the direct use of bio-oil as conventional fuel remains unfavorable because of its corrosive properties, high viscosity, and instability [4]. Therefore, many past research were centered on the development of catalysis material that can effectively upgrade the quality of bio-oil generated during the pyrolysis of $\alpha$-cellulose.

Along with catalysts like zeolite and silicon aluminate, mesoporous silica (MS) MCM-41 is included as materials that showed great results in producing high yield of high-quality bio-oil during the pyrolysis of $\alpha$-cellulose due to its high specific surface area [6]. Former study has particularly highlighted the desirable increase of furan production as a valuable chemical product with the use of MCM-41 catalyst. Despite the good catalytic activity, the common expensive synthesis process of mesoporous silica that comes with the need for tetraethyl orthosilicate (TEOS) as silica source has put a drawback to its wide application. In overcoming this issue, proposing an alternative silica source that is low cost and highly available can be a very interesting subject to look into.

Rice husk ash (RHA) is a massively produced agricultural waste from rice production that is known to contain silica with $20-25 \mathrm{wt} \%$ content [7]. The harmful nature of this waste has instigated many efforts to avoid its disposal in the environment $[8,9]$. Based on this consideration, employing the low value RHA waste in the preparation of MS catalysis material is such an attractive idea that solves both economical and environmental problems [10]. Through a reaction with base, silica can be successfully extracted from natural ingredients as sodium silicate [11]. The negatively charged oxygen composing the structure of sodium silicate can easily be directed to form a mesoporous structure through its active interaction with a positively-charged surfactant like cetyltrime- thylammonium bromide (CTAB) via liquid crystal templating (LCT) [12]. The differences in silica material and CTAB concentration highly affect the character of MS produced from the synthesis process. Although these effects have been thoroughly studied in the preparation of MS from many other silica sources, such as: fly ash [13], natural diatomite [14], natural zeolite, TEOS [15], bagasse, and rice husk, no many research were done on the utilization of RHA.

Therefore, in this work, the preparation of MS as catalyst in the pyrolysis of $\alpha$-cellulose was carried out using RHA as silica source and CTAB surfactant as structure directing agent. Firstly, RHA was dissolved in a strong base solution at a moderate temperature to obtain sodium silicate. The product was then mixed in a CTAB solution at various concentration to produce multiple white powder MS catalysts with different characters after calcination. Many characterization procedures were employed in determining the properties that each prepared catalysis materials possessed. The effect of these properties to the catalytic activity of MS is also evaluated in the pyrolysis of $\alpha$-cellulose at high temperature. From this work, the use of a high performing MS catalyst prepared from RHA in the pyrolysis of $\alpha$-cellulose is expected to provide a cost-effective and environmentally friendly production of high-quality bio-oil from a highly available biomass.

\section{Materials and Methods}

\subsection{Materials}

In this work, the RHA was collected from the burning of rice husks in Bogor, West Java. Sodium hydroxide p.a. $(\mathrm{NaOH},>97 \%)$, hydrochloric acid $(\mathrm{HCl}, 37 \%)$, and $\alpha$-cellulose were purchased from Merck. CTAB $\left(\mathrm{C}_{16} \mathrm{H}_{33}\left(\mathrm{CH}_{3}\right)\right.$ $3 \mathrm{NBr}$ ) surfactant was provided by Himedia.

\subsection{Methods}

\subsubsection{Extraction of sodium silicate}

In the extraction of sodium silicate, 16.6. $\mathrm{g}$ of rice husk ash was added along with $20 \mathrm{~g}$ of $\mathrm{NaOH}$ to a $200 \mathrm{~mL}$ of aqueous solution. They were dissolved and reacted at $80^{\circ} \mathrm{C}$ in a reflux system for $2 \mathrm{~h}$ in an accordance to a previously published method [10]. The mixture solution was then cooled and separated from its solid residue through a centrifugation.

\subsubsection{Synthesis of mesoporous silica (MS)}

CTAB powder was weighed and dissolved in $15 \mathrm{~mL}$ distilled water under constant stirring 
for 15 minutes. The solution was then added with a dropwise of the previously prepared sodium silicate with varying $\mathrm{CTAB}: \mathrm{SiO}_{2}$ mole ratio: $0.05: 1 ; 0.1: 1 ; 0.2: 1$ and stirred to homogeneous. After 30 minutes, the $\mathrm{pH}$ of the mixture solution was adjusted to 10 using $1 \mathrm{M}$ of $\mathrm{HCl}$ and stirred for $2 \mathrm{~h}$. Afterwards, the mixture was sat at room temperature for $24 \mathrm{~h}$ for an aging process. The white precipitation formed, marked as SC (silica+CTAB), was then filtered, washed by distilled water, and dried and dried at $60{ }^{\circ} \mathrm{C}$ overnight. Eventually, SC was calcined at $550{ }^{\circ} \mathrm{C}$ for $6 \mathrm{~h}$ to remove surfactant template and obtain a mesoporous silica (MS) [16]. From this process, three MS, labelled as MS (0.05:1); MS (0.1:1); MS (0.2:1) were collected.

\subsubsection{Pyrolysis of $\alpha$-cellulose}

In this study, the pyrolysis of $\alpha$-cellulose was done at $450{ }^{\circ} \mathrm{C}$ using a Py-GCMS with a
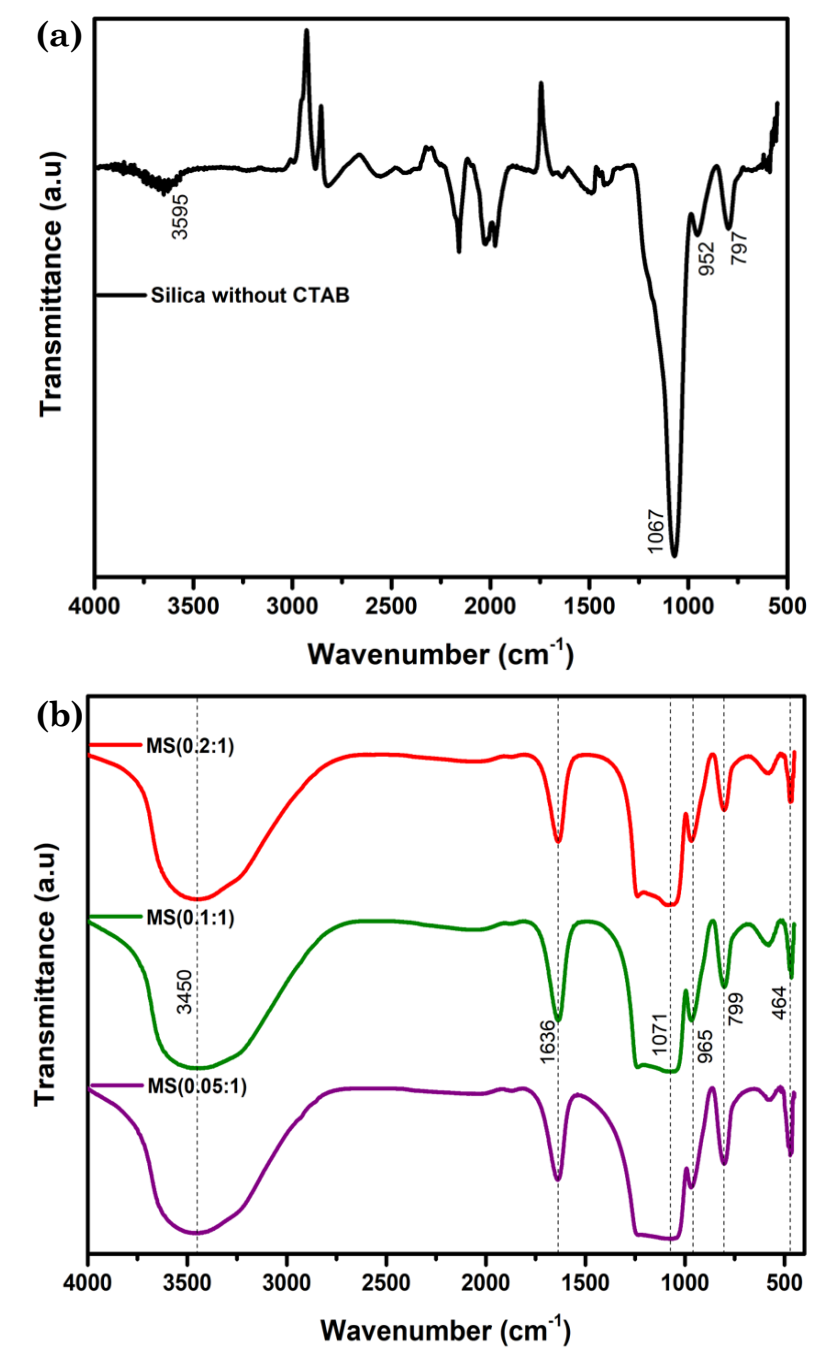

quartz pyrolysis tube $[1,17]$. The GCMS instrument consists of a capillary column $(60 \mathrm{~m} ; 0.25$ $\mathrm{mm} ; 0.25 \mu \mathrm{m}$ ), helium UHP as the carrier gas, a split injector ratio of 1:50, and an injector temperature of $280^{\circ} \mathrm{C}$. Pyrolysis in the absence as well as in the presence of MS are both observed. The mass ratio of MS: $\alpha$-cellulose used was $1: 10$. The samples were put into a sample cup in the auto-shot sampler before entering the heated zone. The sample cup will automatically fall into the pyrolysis furnace through a valve that operates sequentially.

\subsubsection{Catalyst characterization}

The functional groups of all MS were characterized by Fourier transform infrared spectroscopy (FTIR) (Thermo Scientific) spectra recorded in the $4000-400 \mathrm{~cm}^{-1}$ range using the $\mathrm{KBr}$ pellet method. Nitrogen adsorptiondesorption isotherm of all samples were determined using a surface area analyzer (SAA) (JWGB Meso 112) on mesoporous silica degassed at $300{ }^{\circ} \mathrm{C}$ for 3 hours. The data obtained from surface area analysis was used to quantify pore volume as well as specific surface area using Brunauer-Emmett-Teller (BET) and Barrett-Joyner-Halenda (BJH) method. The surface morphology of MS was captured using a scanning electron microscope (SEM) (ZEISS). Meanwhile, the catalytic activity test was evaluated using Py-GCMS (SHIMADZU) instrument.

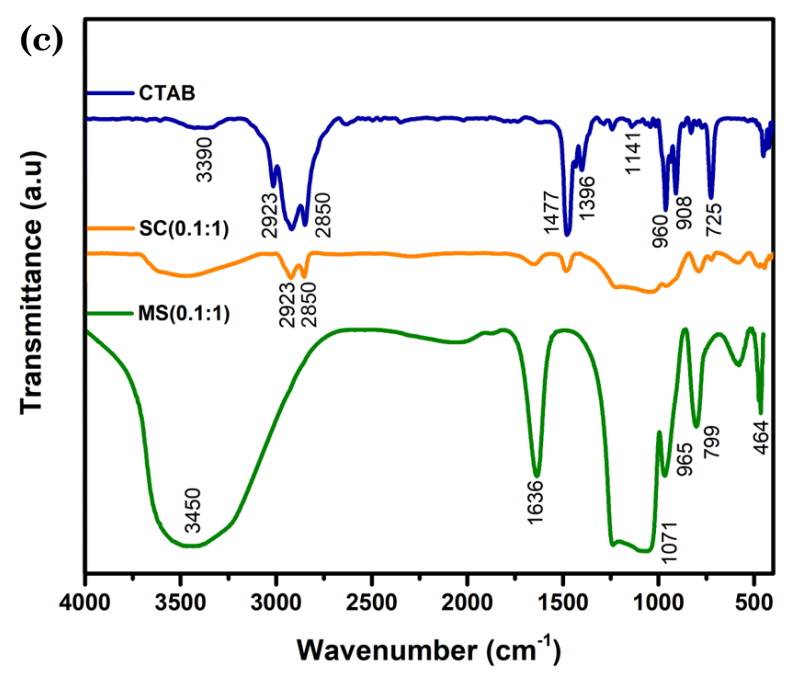

Figure 1. FTIR spectra (a) silica without CTAB; (b) mesoporous silica (MS) with three variations of CTAB: $\mathrm{SiO}_{2}$ ratio mole; (c) spectra of pure CTAB, SC (silica+CTAB) (0.1:1), and mesoporous silica with CTAB: $\mathrm{SiO}_{2}$ ratio mole of $0.1: 1$ (MS 0.1:1). 


\section{Results and Discussion}

\subsection{Effect of Mole Ratio Variations of CTAB: $\mathrm{SiO}_{2}$}

The silica without CTAB FTIR spectrum is shown in Figure 1(a) that consist of siloxane ( $\mathrm{Si}-\mathrm{O}-\mathrm{Si})$ groups reveals at $1067 \mathrm{~cm}^{-1}$ (ustretching asymmetry) and $797 \mathrm{~cm}^{-1}$ (ustretching symmetry), silanol $(\mathrm{Si}-\mathrm{OH})$ groups at $952 \mathrm{~cm}^{-1}$, and hydroxyl group $(-\mathrm{OH})$ of silanol and water at $3595 \mathrm{~cm}^{-1}$ (ustretching). The functional groups constructing all MS prepared using three different CTAB: $\mathrm{SiO}_{2}$ mole ratio were observed with FTIR as shown in Figure 1(b). All materials displayed the bending, asymmetric and symmetric stretching vibration band of siloxane ( $\mathrm{Si}-\mathrm{O}-\mathrm{Si}$ ) at wavenumber 464 , $1242,1071 \mathrm{~cm}^{-1}$, respectively, as well as the symmetric stretching of silanol group at 965 $\mathrm{cm}^{-1}$. On the other hand, the vibration bands appeared at $1636 \mathrm{~cm}^{-1}$ and $3450 \mathrm{~cm}^{-1}$ indicated the presence of $\mathrm{O}-\mathrm{H}$ vibration band from adsorbed water on the surface of MS catalysts $[10,13,16,18]$. Furthermore, a distinction of spectrum was found in the vibration of MS before (SC) and after calcination. Three prominent bands formed by the symmetric and asymmetric stretching of $\mathrm{C}-\mathrm{H}$ as well as the stretching of $\mathrm{CN}$ bond at wavenumber 2923, 2850, and

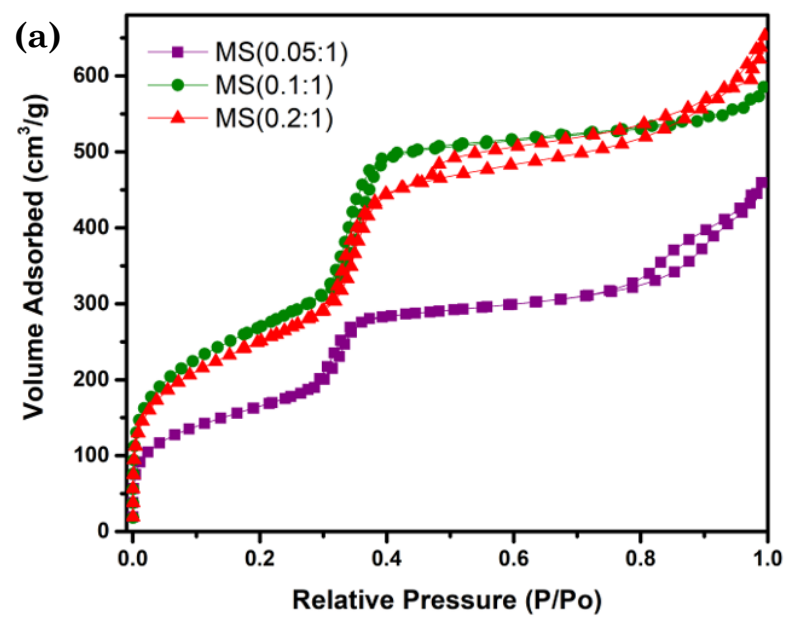

$1477 \mathrm{~cm}^{-1}$, respectively, were not found in the spectrum of MS after calcination process. In an attempt to explain this data, CTAB spectrum was observed to be used as a reference (Figure 1(c)) [19]. Through comparison, it is obvious that the disappearing $\mathrm{C}-\mathrm{H}$ and $\mathrm{CN}$ bond in a calcined MS belongs to the structure of surfactant compound that is inevitably decomposed at high temperature. The result indicated the success of calcination in removing CTAB compound to generate a vacant MS with an available active surface site.

The mesoporous structure of MS can be confirmed through its nitrogen adsorptiondesorption isotherm graphs displayed in Figure 2(a). It is seen that all materials exhibited Type IV isotherm model with a clear hysteresis loop which, according to IUPAC classification, corresponds to the structure of mesoporous material. The correlation coefficient for BET surface area is about 0.995. From its low $\mathrm{N}_{2}$ adsorption volume, isotherm graph has also hinted that MS (0.05:1) possessed the lowest surface area among the other catalysts. This was evidently confirmed by BET calculation listed in Table 1. The surface area of MS reached a maximum with the use of $0.1 \mathrm{CTAB}$ ratio before generating a significant decline in the use of a higher surfactant concentration. Similarly,

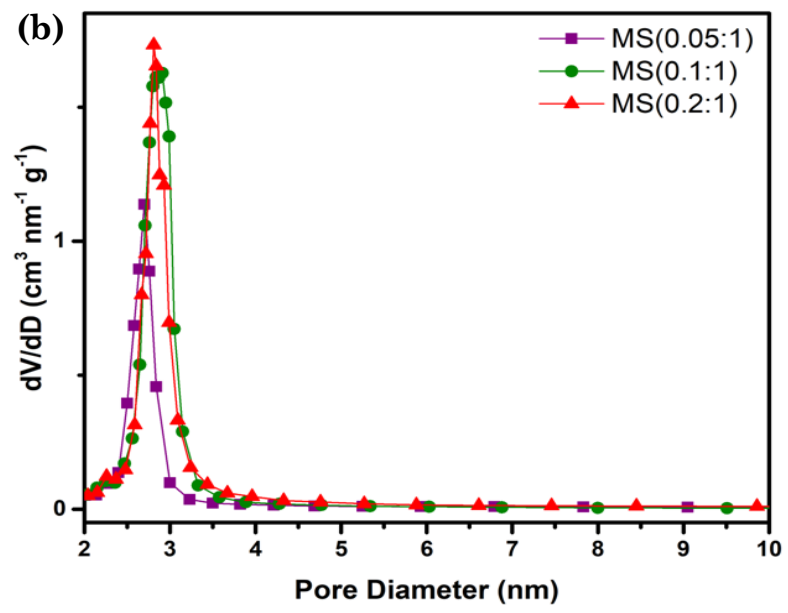

Figure 2. Mesoporous silica (MS) with three variations of CTAB: $\mathrm{SiO}_{2}$ ratio mole; (a) $\mathrm{N}_{2}$ adsorptiondesorption isotherm and (b) silica pore distribution.

Table 1. Pore properties from $\mathrm{N}_{2}$ adsorption-desorption of mesoporous silica (MS) with three variations of CTAB: $\mathrm{SiO}_{2}$ ratio mole.

\begin{tabular}{lccc}
\hline Sample & $\begin{array}{c}\text { Specific surface area } \\
\left(\mathrm{m}^{2} / \mathrm{g}\right)\end{array}$ & $\begin{array}{c}\text { Average pore diameter } \\
(\mathrm{nm})\end{array}$ & $\begin{array}{c}\text { Total pore volume } \\
\left(\mathrm{cm}^{3} / \mathrm{g}\right)\end{array}$ \\
\hline MS $(0.05: 1)$ & 604.443 & 4.698 & 0.710 \\
MS $(0.1: 1)$ & 970.802 & 3.692 & 0.896 \\
MS $(0.2: 1)$ & 907.012 & 4.368 & 0.990 \\
\hline
\end{tabular}


BJH calculation had also shown a gradual increase of pore volume along with the increase of CTAB ratio. The increase of surface area and pore volume that comes with employing higher CTAB concentration is naturally expected as it creates a greater amount of template that facilitates the formation of more mesoporous structures. However, the drop of surface area found in MS (0.2:1) suggested a less effective mesoporous structure directing process possibly due to the presence of excessive CTAB molecules that create an undesirable disturbance in the interaction between sodium silicate and surfactant. Therefore, among the three condition, it is obvious that $0.1: 1$ was the most optimum CTAB: $\mathrm{SiO}_{2}$ mole ratio to be used in the synthesis of MS from RHA.
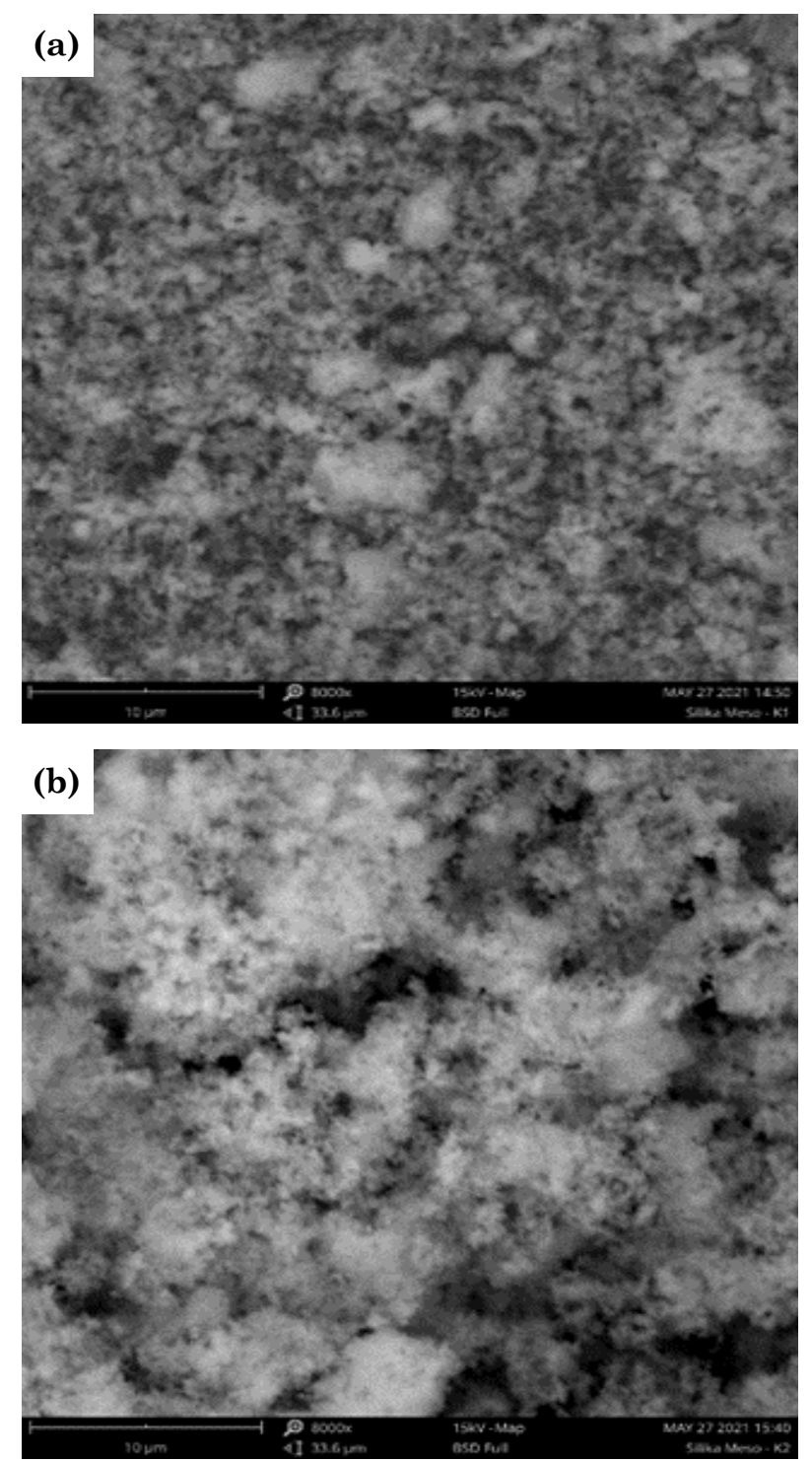

The uniformity of pore size was well portrayed in the pore size distribution graph of all MS materials as shown in Figure 2(b). As expected, the narrowest pore distribution curve, which suggests the best uniformity, was shown by MS prepared in the most optimum condition (0.1:1). The high order of MS (0.1:1) prevents the formation of larger sized pores in the material, which explains the low average pore diameter in comparison to the other MS catalysts. The surface morphology of all MS captured by SEM (Figure 3), revealed a coral-reefs-like structure with irregular and agglomerated particles that is similar to the material found in the study by Arunmetha et al. [20].

\subsection{Pyrolysis of $\alpha$-Cellulose with Mesoporous Silica}

In this study, the catalytic activity of MS prepared from RHA was evaluated in the pyrolysis of $\alpha$-cellulose carried out at $450{ }^{\circ} \mathrm{C}$ (Table 2). Exhibiting the highest surface area, MS (0.1:1) was selected as the best catalyst to be explored further. To detect a performance enhancement and differences, the results obtained from pyrolysis with and without catalyst material were specifically compared. All compounds that are composing the pyrolysis products were identified using Py-GCMS in order to obtain information of which reaction route each pyrolysis underwent.

Generally, pyrolysis of $\alpha$-cellulose was shown to produce bio-oil that is predominantly composed by aliphatic hydrocarbon and several oxygenated compounds such as levoglucosan, furans, acetic acid as well as ketones. The pres-

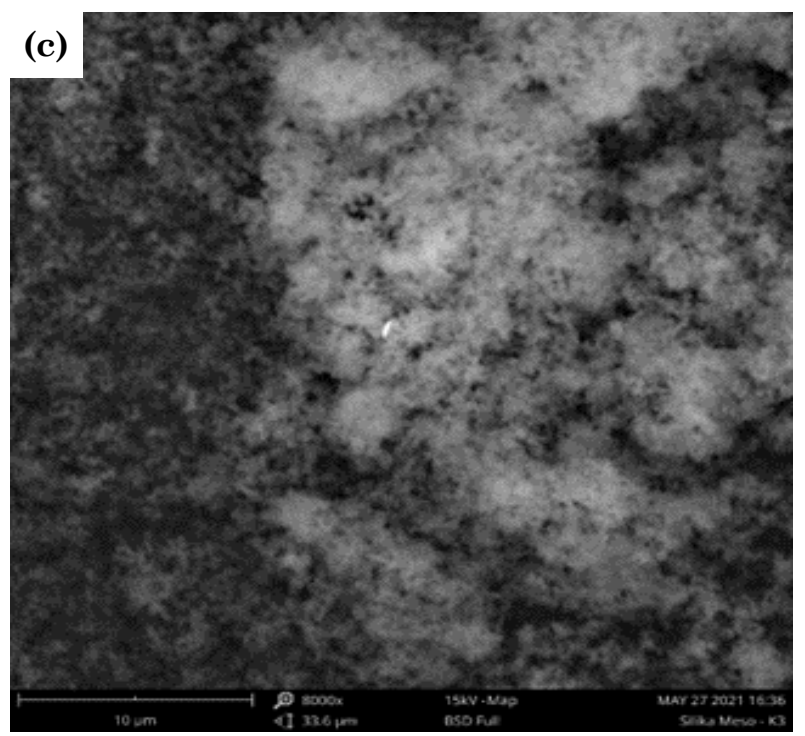

Figure 3. SEM mesoporous silica (MS) with three variations of CTAB:SiO 2 ratio mole; (a) MS (0.05:1); (b) MS (0.1:1); (c) MS (0.2:1). 
Table 2. The $\alpha$-cellulose product with catalytic and non-catalytic pyrolysis

\begin{tabular}{|c|c|c|c|c|}
\hline \multirow{2}{*}{ No. } & \multirow{2}{*}{ Compound } & \multirow{2}{*}{ Molecular formula } & \multicolumn{2}{|c|}{ Concentration (\%) } \\
\hline & & & $\alpha$-Cellulosa & $\operatorname{MS}(0.1: 1)$ \\
\hline 1. & Carbon dioxide & $\mathrm{CO}_{2}$ & 7.63 & 8.35 \\
\hline \multirow[t]{6}{*}{2.} & Aliphatic hydrocarbon & & 13.83 & 6.19 \\
\hline & Butane, 2-methyl- & $\mathrm{C}_{5} \mathrm{H}_{12}$ & 4.2 & - \\
\hline & Cyclooctane & $\mathrm{C}_{8} \mathrm{H}_{16}$ & 0.8 & 1.18 \\
\hline & Propane, 2-methyl- & $\mathrm{C}_{4} \mathrm{H}_{10}$ & 3.73 & 5.01 \\
\hline & 1-Octene & $\mathrm{C}_{8} \mathrm{H}_{16}$ & 4.1 & - \\
\hline & 1,1-Dibutoxyethane & $\mathrm{C}_{10} \mathrm{H}_{22} \mathrm{O}_{2}$ & 1.00 & - \\
\hline \multirow[t]{12}{*}{3.} & Ketones & & 10.26 & 10.87 \\
\hline & 2-Hexanone & $\mathrm{C}_{6} \mathrm{H}_{12} \mathrm{O}$ & - & - \\
\hline & 5-Hexen-2-one & $\mathrm{C}_{6} \mathrm{H}_{10} \mathrm{O}$ & 1.22 & - \\
\hline & Cyclopetanone, 2-methyl- & $\mathrm{C}_{6} \mathrm{H}_{10} \mathrm{O}$ & 2.5 & 3.38 \\
\hline & Cyclopentanone, 3-methyl- & $\mathrm{C}_{6} \mathrm{H}_{10} \mathrm{O}$ & - & 1.52 \\
\hline & 2-Propanone,1-hydroxyl- & $\mathrm{C}_{3} \mathrm{H}_{6} \mathrm{O}_{2}$ & - & 1.23 \\
\hline & 2-Butanone, 3-methyl- & $\mathrm{C}_{5} \mathrm{H}_{10} \mathrm{O}$ & 2.58 & 2.53 \\
\hline & 2-Pentanone, 4-methyl- & $\mathrm{C}_{6} \mathrm{H}_{12} \mathrm{O}$ & - & 2.21 \\
\hline & Ethanone, 1-(3-butyloxiranyl)- & $\mathrm{C}_{8} \mathrm{H}_{14} \mathrm{O}_{2}$ & 1.15 & - \\
\hline & Ethanone, 1-(methylenecyclopropyl) & $\mathrm{C}_{6} \mathrm{H}_{8} \mathrm{O}$ & - & - \\
\hline & Ethenone & $\mathrm{C}_{2} \mathrm{H}_{2} \mathrm{O}$ & - & - \\
\hline & 2-Pentanone, 4-methyl- & $\mathrm{C}_{6} \mathrm{H}_{12} \mathrm{O}$ & 2.81 & - \\
\hline \multirow[t]{2}{*}{4.} & Carboxylic acid & & 3.32 & 3.34 \\
\hline & Acetic acid, anhydride & $\mathrm{C}_{4} \mathrm{H}_{6} \mathrm{O}_{3}$ & 3.32 & 3.34 \\
\hline \multirow[t]{5}{*}{5.} & Furan & & 6.2 & 7.22 \\
\hline & $\begin{array}{l}2,5 \text {-dimethyl-4-hydroxy-3(2H)- } \\
\text { furanone }\end{array}$ & $\mathrm{C}_{6} \mathrm{H}_{8} \mathrm{O}_{3}$ & 1.03 & 2.98 \\
\hline & 2-Furanmethanol & $\mathrm{C}_{5} \mathrm{H}_{6} \mathrm{O}_{2}$ & 3.02 & - \\
\hline & 2(3H)-Furanone, dihydro- & $\mathrm{C}_{4} \mathrm{H}_{6} \mathrm{O}_{2}$ & 2.15 & - \\
\hline & 2-Furancarboxaldehyde, 5-methyl- & $\mathrm{C}_{6} \mathrm{H}_{6} \mathrm{O}_{2}$ & - & 4.24 \\
\hline \multirow[t]{5}{*}{6.} & Aldehide & & 3.4 & 9.75 \\
\hline & Heptanal & $\mathrm{C}_{7} \mathrm{H}_{14} \mathrm{O}$ & 3.4 & 6.38 \\
\hline & Octanal & $\mathrm{C}_{8} \mathrm{H}_{16} \mathrm{O}$ & - & 2.03 \\
\hline & Pentanal & $\mathrm{C}_{5} \mathrm{H}_{10} \mathrm{O}$ & - & - \\
\hline & Butanal, 3-methyl- & $\mathrm{C}_{5} \mathrm{H}_{10} \mathrm{O}$ & - & 1.34 \\
\hline \multirow[t]{2}{*}{7.} & Anhydrous sugars & & 54.87 & 46.35 \\
\hline & $\begin{array}{l}\text { 1,6-anhydro-beta-d-glucopyranose } \\
\text { (levoglucosan) }\end{array}$ & $\mathrm{C}_{6} \mathrm{H}_{10} \mathrm{O}_{5}$ & 54.87 & 46.35 \\
\hline \multirow[t]{2}{*}{8} & Ester & & 0.49 & - \\
\hline & $\begin{array}{l}\text { Pentanoic acid, 2-hydroxy-3-methyl-, } \\
\text { methyl ester }\end{array}$ & $\mathrm{C}_{7} \mathrm{H}_{14} \mathrm{O}_{3}$ & 0.49 & - \\
\hline \multirow[t]{5}{*}{9.} & Alcohol & & - & 7.94 \\
\hline & 3-Buten-1-ol & $\mathrm{C}_{4} \mathrm{H}_{8} \mathrm{O}$ & - & 1.13 \\
\hline & 1-Hexanol & $\mathrm{C}_{6} \mathrm{H}_{14} \mathrm{O}$ & - & 5.65 \\
\hline & 2-Heptanol & $\mathrm{C}_{7} \mathrm{H}_{16} \mathrm{O}$ & - & 1.16 \\
\hline & Total & & 100 & 100 \\
\hline
\end{tabular}


ence of levoglucosan and acetic acid in the product implied the occurrence of depolymerization and deacetylation reactions, respectively [4]. However, the difference in the pyrolysis performed with and without MS catalyst was especially seen in the generation of furan compound that increase in the latter condition (Figure 4). According to former study, furan is the product obtained from the dehydration of sugar [6]. The increase of furan compounds found in the liquid product obtained from a catalyzed pyrolysis over MS (0.1:1) highlighted a high water adsorption by the catalyst that induces dehydration reaction. Moreover, the types of furan present in the liquid product were also varied in non- and catalyzed pyrolysis of $\alpha$-cellulose. While a non-catalyzed pyrolysis produced 3 types of furans (2,5-dimethyl-4hydroxy-3(2H)-furanone, 2-Furanmethanol, $2(3 \mathrm{H})$-Furanone, dihydro), the catalyzed process released 2 types that includes 2,5dimethyl-4-hydroxy-3(2H)-furanone and 2Furancarboxaldehyde, 5-methyl as an addition. Furancarboxaldehyde particularly dominates the furan composition in the product of MScatalyzed pyrolysis. Furan is a valuable chemical that can be used as a precursor to synthesize many other chemical compounds. Therefore, its production is considered desirable.
Overall, pyrolysis over MS catalyst was shown to produce higher level of oxygenated compounds. This is likely due to the high surface area and porous structure provided by MS that leads to the increase of diffusion limits, which improves the interactions between reactants and active sites, thus, facilitating macromolecular reaction involving large volumes of molecules [21,22]. In addition to furan, ketones and alcohol are also obtained in a higher number in the catalyzed pyrolysis. This is in an agreement to the study by Chi et al. [6]. The result is a clear depiction of MS behavior that actively initiates ring opening of sugar, which is also indicated by the $10 \%$ decrease of levoglucosan in the product [21]. With high level of furan, alcohol, and ketones that have such a wild application in many fields [23-25], bio-oil obtained from the pyrolysis of cellulose over MS has such a high economical value through an industrial standpoint.

As previously mentioned, aside from oxygenated compounds, aliphatic hydrocarbons, predominantly 2-methylpropane, were also produced during the pyrolysis of $\alpha$-cellulose. These compounds are highly preferred for fuel composition due to its high octane number [4]. However, the level of aliphatic hydrocarbon compounds found in the bio-oil of MS-catalyzed

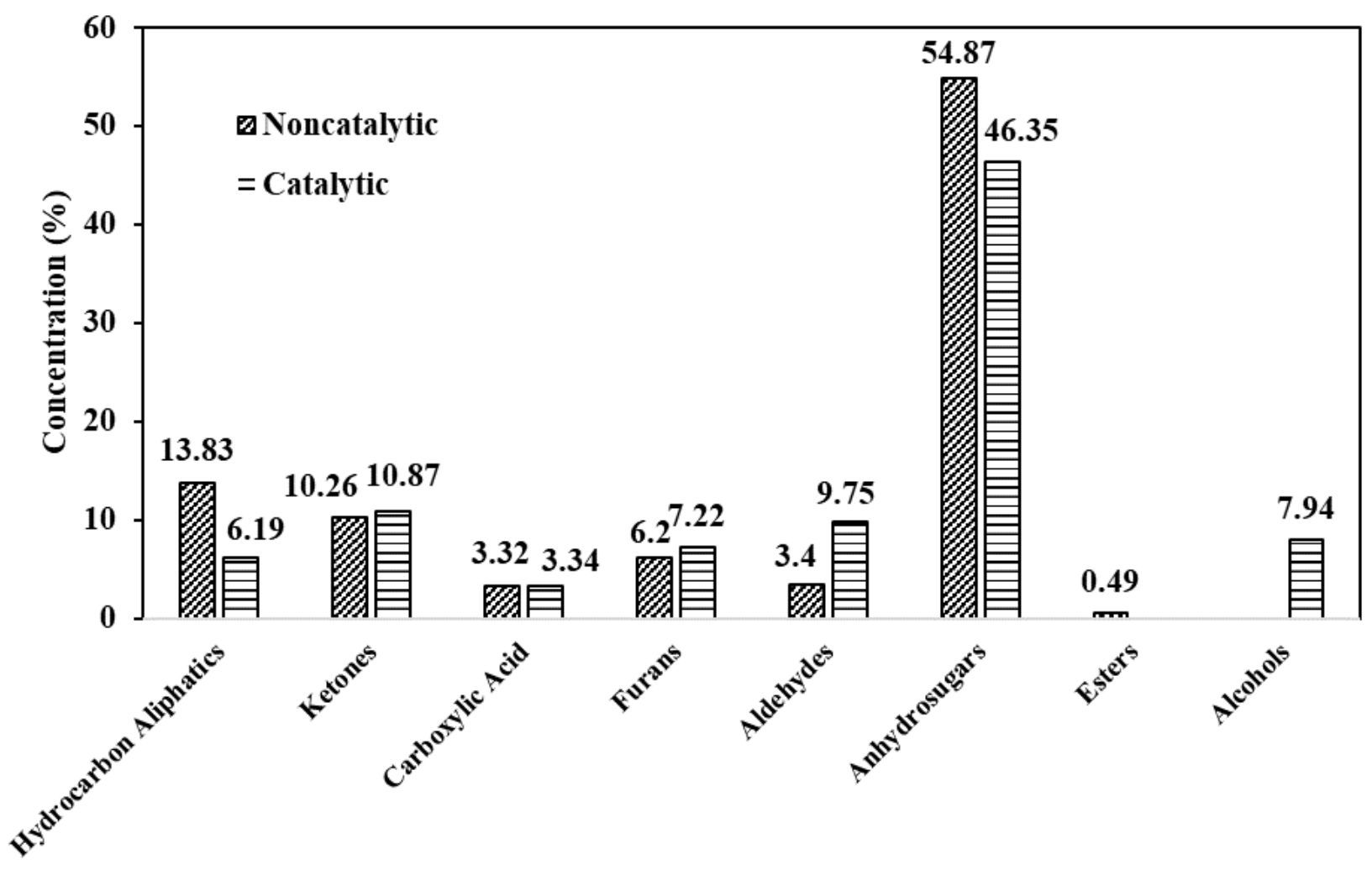

Figure 4. Distribution product of catalytic and non-catalytic pyrolysis $\alpha$-cellulose. 
pyrolysis was lower than that obtained in the uncatalyzed process (Table 1). The data demonstrated the low selectivity of MS towards deoxygenation reaction that produces hydrocarbon, which opens up many research potential for its enhancement in the future.

\section{Conclusion}

In this work, mesoporous silica (MS) catalyst was prepared from rice husk ash (RHA) waste for the pyrolysis of $\alpha$-cellulose at $450{ }^{\circ} \mathrm{C}$. It was found that the best MS from RHA, with BET surface area, pore diameter, and pore volume of $970.802 \mathrm{~m}^{2} / \mathrm{g} ; 3.692 \mathrm{~nm} ; 0.896 \mathrm{~cm}^{3} / \mathrm{g}$, respectively, was obtained in the synthesis using 0.1:1 CTAB: $\mathrm{SiO}_{2}$ mole ratio. The bio-oil obtained from the pyrolysis of $\alpha$-cellulose with and without MS catalyst were shown to differ in its composition. The use of MS, for instance, enhanced the production of oxygenated compounds, such as furan, alcohol, and ketones, that are all valuable due to their wide application. It is especially noticed in the furan production that increased by two times in the MScatalyzed pyrolysis of $\alpha$-cellulose. In contrast to oxygenated compounds, hydrocarbon level was shown to decrease with the use of MS. The result indicated the low deoxygenation selectivity portrayed by MS catalyst. From this work, a cost-effective and environmentally friendly catalysis material from RHA waste was provided for the conversion of biomass to produce a valuable chemical compounds and an alternative fuel.

\section{Acknowledgments}

The authors would like to thank the Ministry of Research and Technology of Republic Indonesia (KEMENRISTEK-BRIN) for the financial support through Konsorsium Riset Perguruan Tinggi scheme with contract number 198/SP2H/LT/DRPM/2021.

\section{References}

[1] Kaewpengkrow, P., Atong, D., Sricharoenchaikul, V. (2017). Selective catalytic fast pyrolysis of Jatropha curcas residue with metal oxide impregnated activated carbon for upgrading bio-oil. International Journal of Hydrogen Energy, 42(29), 18397-18409. DOI: 10.1016/j.ijhydene.2017.04.167

[2] Mckendry, P. (2002). Energy production from biomass (part 1): overview of biomass. Bioresource Technology, 83, 37-46. DOI: 10.1016/S0960-8524(01)00118-3.
[3] Bartoli, M., Rosi, L., Giovannelli, A., Frediani, P., Frediani, M. (2016). Pyrolysis of acellulose using a multimode microwave oven. Journal of Analytical and Applied Pyrolysis, $120, \quad 284-296$. D O I : 10.1016/j.jaap.2016.05.016.

[4] Santi, D., Triyono, T., Trisunaryanti, W., Izul Falah, I. (2020). Hydrocracking of pyrolyzed a-cellulose to hydrocarbon over $\mathrm{MxOy} / \mathrm{Mesoporous}$ carbon catalyst $(\mathrm{M}=\mathrm{Co}$ and Mo): Synthesis and characterization of carbon-based catalyst support from saw waste of Merbau wood. Journal of Environmental Chemical Engineering, 8(3), 103735. DOI: $10.1016 /$ j.jece.2020.103735

[5] Lyu, G., Wu, S., Zhang, H. (2015). Estimation and comparison of bio-oil components from different pyrolysis conditions. Frontiers in Energy Research, 3, 28. DOI: 10.3389/fenrg.2015.00028.

[6] Chi, Y., Xue, J., Zhuo, J., Zhang, D., Liu, M., Yao, Q. (2018). Science of the Total Environment Catalytic co-pyrolysis of cellulose and polypropylene over all-silica mesoporous catalyst MCM-41 and Al-MCM-41. Science of the Total Environment, 633, 1105-1113. DOI: 10.1016/j.scitotenv.2018.03.239

[7] Dhaneswara, D., Fatriansyah, J.F., Situmorang, F.W., Haqoh, A.N. (2020). Synthesis of Amorphous Silica from Rice Husk Ash: Comparing $\mathrm{HCl}$ and $\mathrm{CH}_{3} \mathrm{COOH}$ Acidification Methods and Various Alkaline Concentrations. International Journal of Technology, 11 ( 1 ) $200-208$. D O I : 10.14716/ijtech.v11i1.3335.

[8] Bakar, R.A., Yahya, R., Gan, S.N. (2016). Production of High Purity Amorphous Silica from Rice Husk. Procedia Chemistry, 19, 189-195. DOI: 10.1016/j.proche.2016.03.092.

[9] Hossain, S.K.S., Mathur, L., Roy, P.K. (2018). Rice husk/rice husk ash as an alternative source of silica in ceramics: A review. Journal of Asian Ceramic Societies, 6, 299313. DOI: 10.1080/21870764.2018.1539210.

[10] Suyanta, A., Kuncaka, K. (2011). Utilization of rice husk as raw material in synthesis of mesoporous silicates MCM-41. Indonesian Journal of Chemistry, 11, 279-284. DOI: 10.22146/ijc.21393

[11] Trisunaryanti, W., Falah, I.I., Marsuki, M.F. (2017). Synthesis of Mesoporous SilicaAlumina from Lapindo Mud Using Gelatin from Catfish Bone as a Template: Effect of Extracting Temperature on Yield and Characteristic of Gelatin as well as Mesoporous Silica-Alumina. In $15^{\text {th }}$ International Conference on Environmental Science and Technology. CEST2017_00741. Rhodes, Greece. 
[12] Alothman, Z.A. (2012). A review: Fundamental aspects of silicate mesoporous materials. Materials, 5(12), 2874-2902. DOI: 10.3390/ma5122874.

[13] Majchrzak-Kucȩba, I., Nowak, W. (2011). Characterization of MCM-41 mesoporous materials derived from polish fly ashes. International Journal of Mineral Processing, 101(14 ), $\quad \begin{array}{llllllll} & 0 & 0 & - & 1 & 1 & 1\end{array}$ D O I : 10.1016/j.minpro.2011.09.002

[14] Aboelenin, R.M.M., Fathy, N.A., Farag, H.K., Sherief, M.A. (2017). Preparation, characterization and catalytic performance of mesoporous silicates derived from natural diatomite: Comparative studies. Journal of Water Process Engineering, 19, 112-119. DOI: 10.1016/j.jwpe.2017.07.017.

[15] Vazquez, N.I., Gonzalez, Z., Ferrari, B., Castro, Y. (2017). Synthesis of mesoporous silica nanoparticles by sol-gel as nanocontainer for future drug delivery applications. Boletín de la Sociedad Española de Cerámica y Vidrio, $56, \quad 139-145 . \quad$ D O I : 10.1016/j.bsecv.2017.03.002.

[16] Yang, G., Deng, Y., Ding, H., Lin, Z., Shao, Y., Wang, Y. (2015). A facile approach to synthesize MCM-41 mesoporous materials from iron ore tailing: Influence of the synthesis conditions on the structural properties. Applied Clay Science, 111, 61-66. DOI: 10.1016/j.clay.2015.04.005

[17] Trisunaryanti, W., Armunanto, R., Hastuti, L.P., Ristiana, D.D., Ginting, R.V. (2018). Hydrocracking of a-Cellulose Using $\mathrm{Co}, \mathrm{Ni}$, and Pd Supported on Mordenite Catalysts. Indonesian Journal of Chemistry, 18(1), 166-172. DOI: $10.22146 / \mathrm{ijc} .26491$

[18] Purwaningsih, H., Ervianto, Y., Pratiwi, V. M., Susanti, D., Purniawan, A. (2019). Effect of Cetyl Trimethyl Ammonium Bromide as Template of Mesoporous Silica MCM-41 from Rice Husk by Sol-Gel Method. IOP Conference Series: Materials Science and Engineering, 515, 012051. DOI: 10.1088/1757$899 X / 515 / 1 / 012051$
[19] Campbell, R.A., Parker, S.R.W., Day, J.P.R., Bain, C.D. (2004). External reflection FTIR spectroscopy of the cationic surfactant hexadecyltrimethylammonium bromide (CTAB) on an overflowing cylinder. Langmuir, 20, 87408753. DOI:10.1021/la048680x.

[20] Arunmetha, S., Karthik, A., Srither, R., Vinoth, M., Suriyaprabha, R., Manivasakan, P., Rajendran, V. (2015). Size-dependent physicochemical properties of mesoporous nanosilica produced from natural quartz sand using three different methods. RSC Advances, 5(59), 47390-47397. DOI: 10.1039/b000000x

[21] Xue, J., Zhuo, J., Liu, M., Chi, Y., Zhang, D., Yao, Q. (2017). Synergetic effect of copyrolysis of cellulose and PP over an all- silica mesoporous catalyst MCM-41 using TGFTIR and Py-GC-MS. Energy \& Fuels, 31(9), $\begin{array}{llllllllllllll}9 & 5 & 7 & 6 & - & 9 & 5 & 8 & 4 & \text {. } & \text { D } & \text { O } & \text { I : }\end{array}$ 10.1021/acs.energyfuels.7b01651

[22] Shi, Y., Liu, C., Zhuo, J., Yao, Q. (2020). Investigation of a Ni-Modified MCM-41 Catalyst for the Reduction of Oxygenates and Carbon Deposits during the Co-Pyrolysis of Cellulose and Polypropylene. ACS Omega, 5, $\begin{array}{llllllllllll}2 & 0 & 2 & 9 & 9 & - & 2 & 0 & 3 & 1 & 0\end{array} . \quad$ D O I : 10.1021/acsomega.0c02205

[23] Sarmah, B., Satpati, B., Srivastava, R. (2018). Selective oxidation of biomass-derived alcohols and aromatic and aliphatic alcohols to aldehydes with O2/air using a $\mathrm{RuO2}$-supported $\mathrm{Mn}_{3} \mathrm{O}_{4}$ catalyst, ACS Omega, 3, 7944-7954. DOI: 10.1021/acsomega.8b01009

[24] Lalanne, L., Nyanhongo, G.S., Guebitz, G.M., Pellis, A. (2021). Biotechnological production and high potential of furan-based renewable monomers and polymers. Biotechnology Advances, $48, \quad 107707$. D O I : 10.1016/j.biotechadv.2021.107707

[25] Mohajer, F., Ziarani, G.M., Badiei, A., Ghasemi, J.B. (2021). SBA-Pr-Imine-Furan as an environmental adsorbent of $\mathrm{Pd}(\mathrm{II})$ in aqueous solutions. Environmental Challeng$e s, \quad 3, \quad 1000032 . \quad$ D O I : 10.1016/j.envc.2021.100032 